\title{
Interpretation and Measurement of Redox Intensity in Natural Waters
}

\section{A Comment to T. Frevert's paper "Can the Redox Conditions in Natural Waters be Predicted by a Single Parameter?"}

\section{by Werner Stumm}

Institute for Water Resources and Water Poilution Control, EAWAG, Swiss Federal Institute of Technology, Zürich, Switzerland

Frevert deserves credit for proposing - for equilibrium systems - a distinction between a conceptually defined redox intensity, $\mathrm{p} \varepsilon$, and an operationally defined redox condition under stationary states, pe, as given by the response of a sensor electrode, and for pointing out that pe need not relate to pe.

We would like to re-emphasize $(1,2,3)$ that in defining a redox intensity, $p \varepsilon=-\log \{e\}$, we have treated the electron conceptually as a basic redox component which, as a species in aqueous solution, does not have an existence of its own. Morel (4) has elaborated on the use of the electron as a (phase rule) component in redox reactions. As he shows, it obviously can be treated equivalent to $\mathrm{O}_{2}$, i.e. $\mathrm{O}_{2}=\left(\mathrm{H}^{+}\right)_{-4}\left(\mathrm{e}^{-}\right)_{-4}\left(\mathrm{H}_{2} \mathrm{O}\right)_{2}$. We define (3) pE as "the hypothetical electron activity at equilibrium which measures the relative tendency of a solution to accept or transfer electrons". This free energy change $\Delta G$ can be expressed as a redox potential (electrode potential) in volts (i.e., as a free energy change per mole of electrons associated with a given reduction). Electron activities may be defined in any equilibrium systems where the free activities of reductants $\{$ Red $\}$, and oxidants $\{\mathrm{Ox}\}$, are defined. Thus, $\mathrm{p} \varepsilon$ (like $\mathrm{pH}$ ) is a derivative form of free energy.

Using electrons in redox reactions and as components does not at all imply that such electrons exist as species in waters. In the compilation of "Stability Constants" of the Chemical Society (London), Sillen and Martell (1964) treat the electron as an inorganic ligand and establish an electron activity scale that corresponds to the definition given.

\section{The Electron-Free Energy Diagram, EFE}

As acknowledged by Frevert, equilibrium considerations can greatly aid attempts to understand the redox patterns observed or anticipated in natural waters, and the microbially mediated redox processes.

The right hand scale of Fig. 1 (enlarged in Fig. 2) lists the sequence of redox reactions, calculated for $\mathrm{pH}=7$ from strong reductants at the bottom to strong oxidants at the top; from such a diagram one can see at a glance that $\mathrm{SO}_{4}{ }^{2-}$ can (thermodynamically speaking) oxidize organic carbon $\left(\mathrm{CH}_{2} \mathrm{O}\right)$ to $\mathrm{CO}_{2}$ and that $\mathrm{SO}_{4}{ }^{2-}$ cannot oxidize $\mathrm{HN}_{4}{ }^{+}$ to $\mathrm{NH}_{3}^{-}$.

Fig. 1 may be interpreted as an electron - free energy level diagram. The ordinate measures the energy (expressable in different units $\mathrm{kcal}$ or $\mathrm{kJ} \mathrm{mol}^{-1}$ of electrons, eV 


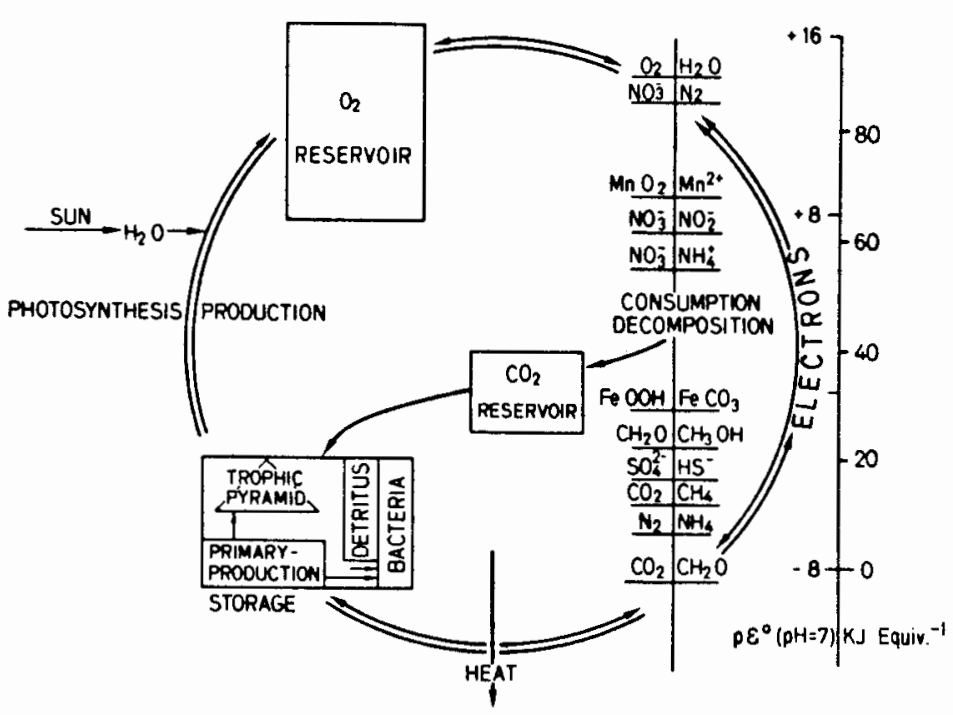

Figure 1: Photosynthesis and biochemical cycle. Photosynthesis may be interpreted as a disproportionation into an oxygen reservoir and reduced organic matter (biomass containing high-energy bonds made with hydrogen and $\mathrm{C}, \mathrm{N}, \mathrm{S}$, and $\mathrm{P}$ compounds). The nonphotosynthetic organisms tend to restore equilibrium by catalytically decomposing the unstable products of photosynthesis through energy-yielding redox reactions.

The $\mathrm{p}_{\varepsilon}{ }^{\circ}$ scale on the right gives the sequence of the redox reactions observed in an aqueous system.

$\mathrm{mol}^{-1}$ and $\mathrm{p} \varepsilon$ units) that is required for the transfer of electrons from one free energy level to another.

If we add electrons (in the form of reductants, i.e. electron complexes) to a system containing several redox couples, the lowest unoccupied electron levels will be filled up sequentially, i.e. the oxidized species will be reduced in sequence, beginning with the species with the lowest unoccupied electron level. Electron - titration diagrams can be prepared. For example, a reductant such as organic carbon (e.g. $\mathrm{CH}_{2} \mathrm{O}$ ) will, from a thermodynamic point of view (but not necessarily from a kinetic point of view) first react with $\mathrm{O}_{2}$, then successively with $\mathrm{NO}_{3}{ }^{-}$and $\mathrm{MnO}_{2}$. The energy gained in such processes per mol of electron transferred can be read from the energy scale:

$$
\Delta \mathrm{G}=2.3 \mathrm{RT}\left(\mathrm{p} \varepsilon_{2}-\mathrm{p} \varepsilon_{1}\right)
$$

The EFE-diagram can be used to predict what reactions are thermodynamically possible. Thus, pe is a parameter that characterizes restrictively the ecological milieu.

A reaction progress model, such as the prediction of the sequence of microbially mediated redox processes, such as the sequential processes of organic matter decomposition in a hypotheticaliy closed aquatic system (i.e. the hypolimnion of a lake), - e.g. oxygen consumption is followed by $\mathrm{NO}_{3}{ }^{-}$-reduction and methane formation - is based on the concept of partical equilibrium. Partial equilibrium describes a state in which a system is in equilibrium with respect to at least one process (or reaction) but out of equilibrium with respect to others. An irreversible process that involves a series of successive partial equilibrium states may result in a state of local equilibrium for the system; that is a state in which no mutually incompatible phases are in contact even though the system as a whole is not in equilibrium (5). 


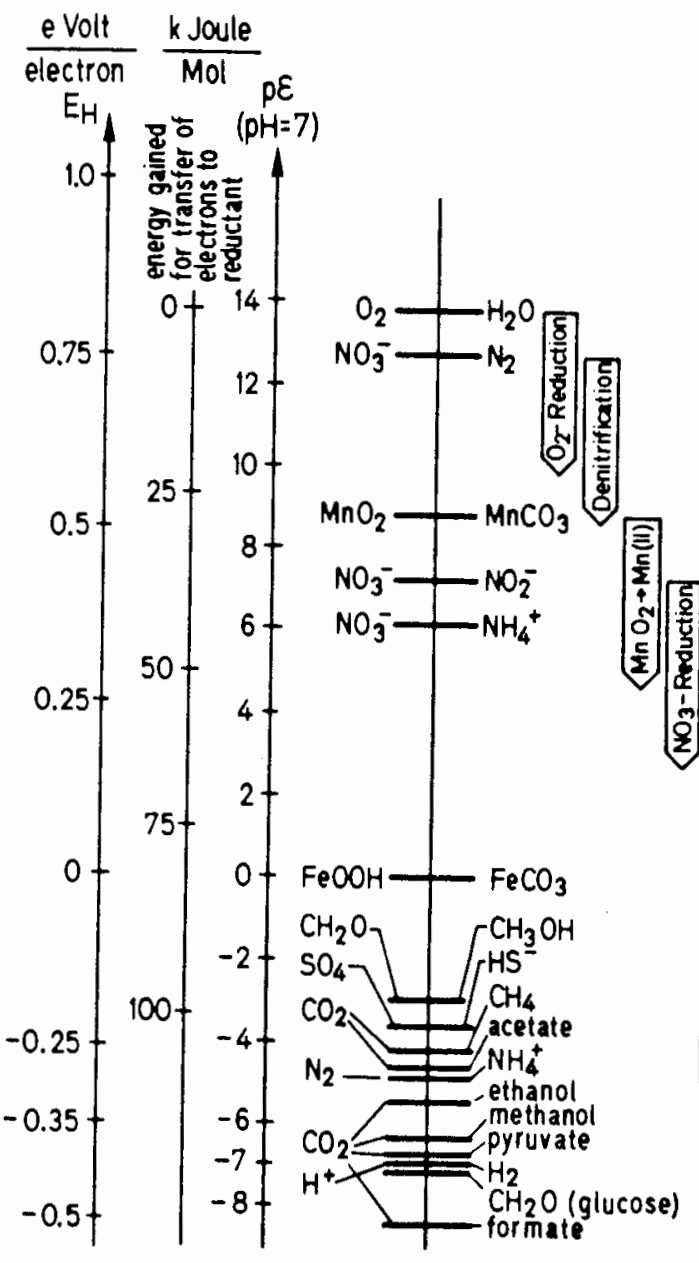

Figure 2: Electron-free Energy Diagramm

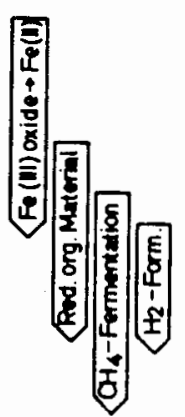

2. Can $p \varepsilon$ be defined for a non-equilibrium system?

In an equilibrium system containing a number of redox couples, the activity of each redox species is a function of (the same) pe. Since many redox processes are very slow in reaching equilibrium and do not couple with one another readily, it is possible to have several different redox levels in the same locale (Figure 3). The various components are obviously not in equilibrium with each other. The system cannot be characterized by a unique $\mathrm{p} \varepsilon$.

From the analysis of the system, various redox intensities, $\left[\mathrm{Ox}_{1}\right] /\left[\operatorname{Red}_{1}\right],\left[\mathrm{Ox}_{2}\right] /\left[\operatorname{Red}_{2}\right]$ etc., can be specified. Which couple is more important to characterize the real system? 


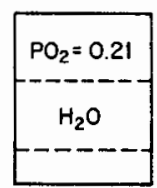

$p €=12.5$

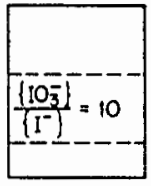

$p \epsilon=10.5$

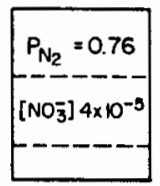

$p \in=10.6$

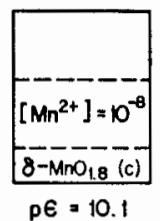

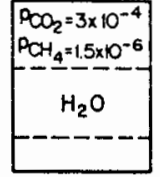

$p \epsilon=-2.85$

$t=25^{\circ} \mathrm{C}$

$\mathrm{pH}=8$

Figure $3: p_{\varepsilon}$ of seawater. Different $p_{\varepsilon}$ values can be calculated for a few activities of redox components of an oxic seawater system (atmosphere, hydrosphere and sediments). It is difficult to characterize the real system by a unique $\mathrm{p}_{\varepsilon}$.

Which couple can exchange electrons with an inert electrode, which one can exchange electrons (or their complexes) with an organism, or which one determines the redox level necessary for a given geochemical process.

\section{Can pe measure the "relevant" or "dominant" redox couple in a natural water?}

Do different "inert" electrodes "feel" the same redox level and does the pe measured by a sensor electrode "sense" the same pe as organisms would "sense"? I think one cannot give an affirmative answer to these simple questions. If we calculate a p $\varepsilon$ or a redox-potential for each analyzed couple and if all computed values agree, rèdox equilibrium exists in the sample; disagreement suggests that the system is not at equilibrium. Figure 4 reproduces data collected by Lindberg and Runnels (7) on normal groundwaters from diverse geographic areas. Nernstian redox potential data computed

\begin{tabular}{|c|c|}
\hline Symbol & Redox couple \\
\hline $\begin{array}{l}0 \\
\nabla \\
0 \\
\square \\
\square \\
\nabla \\
+ \\
\times \\
\dot{0} \\
\mathbf{M}\end{array}$ & $\begin{array}{l}\mathrm{Fe}^{3+} / \mathrm{Fe}^{2+} \\
\mathrm{O}_{2} \mathrm{ad}_{2} \mathrm{O} \\
\mathrm{HS}^{-} / \mathrm{SO}_{4}^{2-} \\
\mathrm{HS}^{-} / \mathrm{S}_{\text {rnmmic }} \\
\mathrm{NO}_{2}^{-} / \mathrm{NO}_{3}^{-} \\
\mathrm{NH}_{4}^{+} / \mathrm{NO}_{3}^{-} \\
\mathrm{NH}_{4}^{+} / \mathrm{NO}_{2}^{-} \\
\mathrm{CH}_{4} \mathrm{aq}_{4} / \mathrm{HCO}_{3}^{-} \\
\mathrm{NH}_{4}^{+} / \mathrm{N}_{2} \mathrm{aq}^{24} \\
\mathrm{Fe}^{2+} / \mathrm{Fe}\left(\mathrm{OH}_{3}\right)_{3}^{(4)} \\
\text { Field-measured Eh value }\end{array}$ \\
\hline
\end{tabular}

Table 1: Redox couples and plotting symbols used in the construction of Fig. 4 (From Lindberg and Runnells (7): SCIENCE, Vol.225, page 926, 31 August 1984, Copyright 1985 by the AAAS.). 


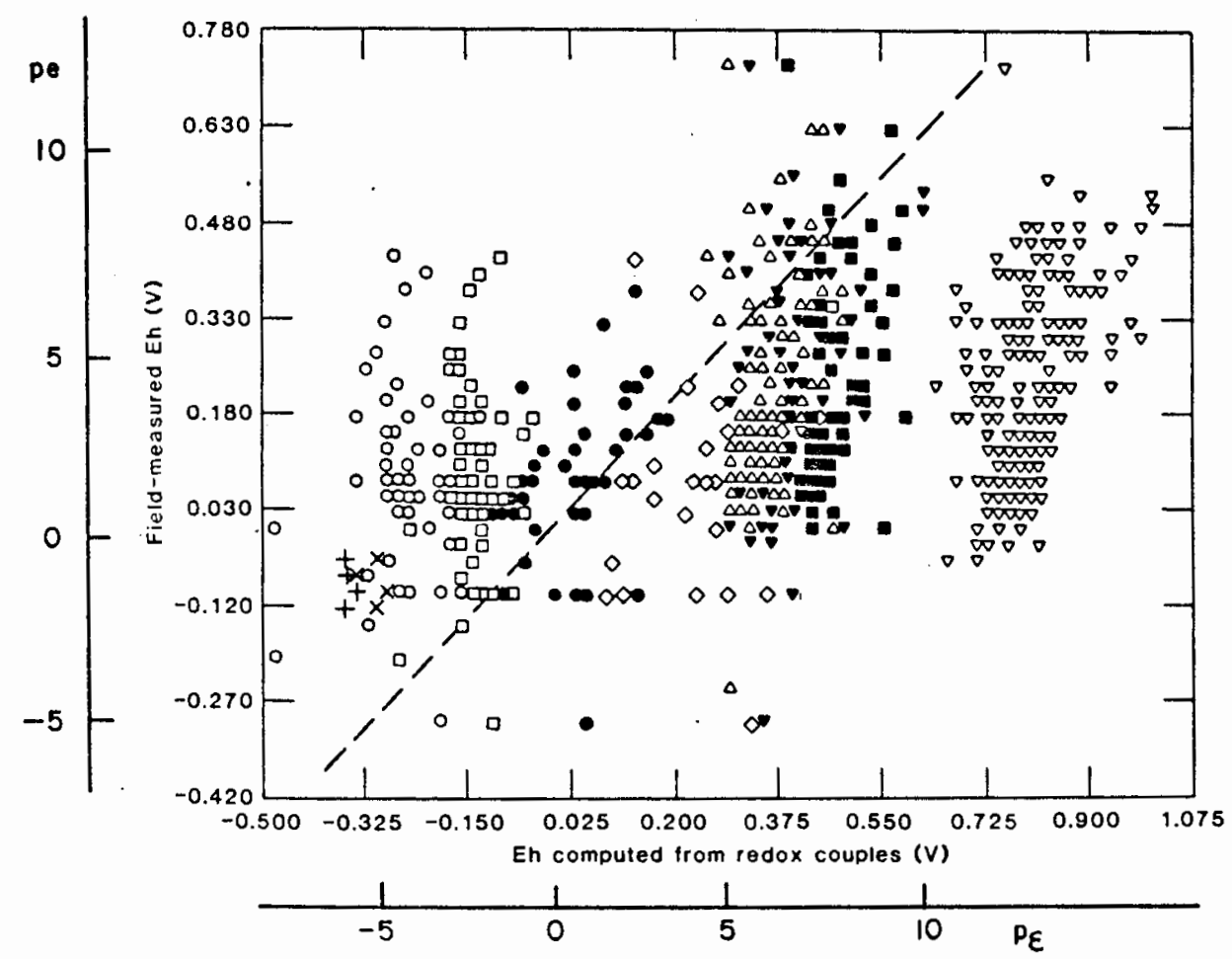

Figure 4: Diagram showing ten computed Nernstian Eh values versus fieldmeasured Eh values for the same samples measured with a platinium electrode. The dashed line is discussed in the text. Symbols and couples are summarized in Table 1. (From Lindberg and Runnells (7): SCIENCE, Vol.225, page 926, 31 August 1984, Copyright 1985 by the AAAS.)

from analytical data of the redox couples (computed pe) present in the system are plotted versus field-measurement redox potential data (measured pe). The dashed line represents the expected locus of points if all computed redox couples were at internal equilibrium and if each computed Nernstian value were to match the field measurement value.

It does not seem possible to relate unambiguously a measured pe to a single redox couple in the natural water system or to that redox couple which is dominant for the ecology or the preponderant redox-mediating microorganisms, because the measured "steady state" potential is given by the redox system with the highest rate of exchange (with the electrode), or the measured potential corresponds to a composite of two or more redox processes (mixed potential). The fact that a $p \varepsilon$ computed from an analyzed "indicator" couple, e.g. $\mathrm{pN}_{2}, \mathrm{NO}_{3}{ }^{-}$or $1^{-}, \mathrm{10}_{3}{ }^{-}$or $\mathrm{Mn}^{2+}, \mathrm{MnO}_{2}$ or $\mathrm{pO}_{2}, \mathrm{H}_{2} \mathrm{O}_{2}$ (of Figure 3) coincides approximately with that of a measured pe, should not be taken as evidence that the electrode now "senses" a master redox couple.

It is as if one were attempting to measure $\mathrm{pH}$ in a system of acids, all of which were not in equilibrium with each other, and where the electrode establishes equilibrium with one acid-base combination but we do not know which one. Also, if we add indicators, 
each indicates a different $\mathrm{pH}(8)$. I believe it is better to measure analytically important redox species, dissolved oxygen, soluble $\mathrm{Fe}^{2+}, \mathrm{Mn}^{2+}$, hydrogen sulfide or methane as guides to the redox status of the waters.

\section{REFERENCES}

1 Stumm, W. (1966), Redox Potential as an Environmental Parameter; Conceptual Significance and Operational Limitation, 3rd Internat. Conf. on Water Pollution Research, Munich, Germany, p. 1-16.

2 Stumm, W. and Morgan, J.J. (1970), Aquatic Chemistry, Wiley, New York (583 p.).

3 Stumm, W. and Morgan, J.J. (1981), Aquatic Chemistry, Wiley, New York (780 p.).

4 Morel, F.M.M. (1967), Principies of Aquatic Chemistry, Wiley, New York (446 p.).

5 Thompson, J. B., Jr., in "Researches in Geochemistry", P. H. Abelson ed., J. Wiley, New York (1959).

6 Stumm, W. (1978), What is the pe of the Sea?. Thalassia Jugoslavica 14, 197-208.

7 Lindberg, R.D. and Runnells, D. D. (1984), Groundwater Redox Reactions, Science 225, $925-927$.

8 Parsons, R. in discussion of Ref. (6), Thalassia Jugoslavica 14, 207 (1978). 